\title{
Toxoplasmosis seroprevalence in Iranian women and risk factors of the disease: a systematic review and meta-analysis
}

\author{
Azadeh Mizani ${ }^{1,2,3}$, Abbas Alipour ${ }^{4}$, Mehdi Sharif ${ }^{1,2}$, Shahabeddin Sarvi ${ }^{1,2}$, Afsaneh Amouei ${ }^{1,2}$, Azar Shokri $^{1,2}$, \\ Mohammad-Taghi Rahimi ${ }^{1,2}$, Seyed Abdollah Hosseini ${ }^{1,2}$ and Ahmad Daryani $i^{1,2^{*}}$
}

\begin{abstract}
Background: Toxoplasmosis is caused by an intracellular obligatory parasite, Toxoplasma gondii, and it has global distribution. The purposes of this systematic review and meta-analysis were to evaluate the seroprevalence of toxoplasmosis in Iranian pregnant women, and girls and women of childbearing age, and identify potentially preventable risk factors.

Methods: Between November 2014 and February 2017, nine electronic databases that reported data on the T. gondii seroprevalence in Iranian women were searched. Our search resulted in 83 reports published from 1994 to 2017.

Results: The results showed that the pooled estimation for the prevalence of $T$. gondii using a random-effect model was $43 \%$ (95\% confidence interval $(\mathrm{Cl})=38-48 \%)$ in pregnant women and $33 \%(95 \% \mathrm{Cl}=23-43 \%)$ in girls and the childbearing age groups. There was a significant association between the T. gondii seroprevalence with age and the gestational age of conception in pregnant women and those who had contact with cats in both groups.

Conclusions: This is the first comprehensive systematic review of T. gondii infection seroprevalence in Iranian women, which showed a high prevalence of Toxoplasma infection. Around $57 \%$ of pregnant women and $67 \%$ of girls and the childbearing age groups were seronegative and thus were susceptible to infection and should be monitored.
\end{abstract}

Keywords: Toxoplasmosis, Toxoplasma gondii, Pregnant women, Women, Girls, Seroprevalence, Systematic review, Iran

\section{Background}

Toxoplasmosis, a cosmopolitan infection in humans and animals, is caused by an intracellular obligatory parasite, Toxoplasma gondii [1]. T. gondii is spread worldwide, as at least one third of the world's population is infected [2]. The broad geographic location of toxoplasmosis is associated with several risk factors such as the geographical climate, contact with cats or other pet's faeces, nutritional habits, and location of one's residence [3]. The worldwide prevalence of antibodies against $T$. gondii varies from 30 to $60 \%$ in both developing and developed countries [4]. Infection is acquired by accidentally ingesting oocysts in food, water, and soil contaminated

\footnotetext{
*Correspondence: daryanii@yahoo.com

'Toxoplasmosis Research Center, Mazandaran University of Medical Sciences,

P. O. Box 48168-95475, Sari, Iran

${ }^{2}$ Parasitology and Mycology Department, School of Medicine, Mazandaran

University of Medical Sciences, Sari, Iran

Full list of author information is available at the end of the article
}

with cat faeces or the consumption of raw meat containing tissue cysts $[5,6]$.

Toxoplasmosis can lead to life-threatening conditions in high-risk groups such as pregnant women, immunodeficient individuals (e.g. HIV-positive patients, organ transplant recipients, and patients with cancer) $[7,8]$. Although T. gondii remains dormant in healthy individuals, exposure to parasites during pregnancy can lead to vertical transmission to the embryo [9]. The incidence of maternal infection during pregnancy is $1-8$ per 1000 pregnancies [10]. A newborn exposed to T. gondii may develop congenital toxoplasmosis with microcephaly, hydrocephaly, blindness, spontaneous abortion, and stillbirth [9]. It may also significantly reduce the quality of life in children who survive prenatal infection and affect the socioeconomic burden on the patient's family and the government [11]. It is important to determine whether infection occurs in the early stage of conception 
or before because women who have been exposed to infection prior to pregnancy are not at risk of having an infected child [12]. Exceptions have been seen in immunodeficient mothers [13]. Screening for anti-Toxoplasma antibodies in pregnant women and also non-immune girls of childbearing age is the mainstay for controlling and preventing congenital infection $[9,11,14]$.

Because of its importance and the fact that $T$. gondii is ubiquitous, seroepidemiologic studies help establish the health policies of each country. The purposes of this systematic review and meta-analysis were as follows: (1) to evaluate the seroprevalence of toxoplasmosis in Iranian pregnant women, (2) to estimate the prevalence of $T$. gondii in girls and women of childbearing age, (3) to identify the potentially preventable risk factors most likely to have the greatest impact on the incidence of Toxoplasma infection in pregnancy, and (4) to determine whether seronegative women are a high-risk group for toxoplasmosis that need specific control and prevention strategies to reduce the level of Toxoplasma infection.

\section{Methods}

The following four literature search strategies were used in this systematic review and meta-analysis: (1) computer search, (2) study selection, (3) data synthesis, and (4) data analysis and quality assessment.

\section{Computer search}

Six English language databases (i.e. PubMed, ScienceDirect, Scopus, Google Scholar, ClinicalTrials.gov, and Cochrane Library) and three Persian databases (i.e. Scientific Information Database, Magiran, and Iran Medex) were searched from 1994 to 2017. The search was restricted to English- and Persian language databases. Medical Subject Heading terms and keywords included Toxoplasma gondii, toxoplasmosis, women, girl, pregnant women, childbearing age women, abortion, seroprevalence, seroepidemiology, Iran, and Islamic Republic of Iran. All citations were downloaded into EndNote.

\section{Study selection}

Abstracts were reviewed independently by 4 authors, and cross-sectional studies that estimated the seroprevalence of Toxoplasma infection in pregnant women, women of childbearing age, women with an abortion, student girls from a university or high school, and girls referred to health centres for premarital laboratory tests or a medical laboratory for routine tests, except $T$. gondii, were selected for further use.

The final decisions about the inclusion or exclusion of studies were made separately after inspection. Discrepancies were resolved by discussion and consensus. In addition, the collected bibliographic publications were screened carefully, and duplicate articles, studies based in Iran, animal-based studies, and those with a specific population (e.g. the general population and all immunocompromised groups) were also excluded.

\section{Data synthesis}

A protocol for data extraction was defined with groups. Data were extracted from selected publications using a data extraction sheet by authors, and then, the data were reviewed by a third author. The following data were extracted from the literature: first author, geographical region, the year of publication, diagnostic method with the cut-off value, total individuals, number of immunoglobulin (Ig)G-positive and IgG-negative cases, number of IgM-positive and IgM-negative cases, and number of both IgG- and IgM-positive cases among the study groups.

All information included demographic factors such as contact with cats and other animals, the consumption of raw fruits and vegetables, washing methods, the consumption of undercooked meat and unpasteurized milk, age, occupational group, education level, place of residence, number of pregnancies and abortions, and gestation age of the total individuals and positive cases. Whether the subjects wore gloves when cutting meat and had contact with soil was also collected. Figure 1 shows a diagram describing the study design process.

\section{Data analysis and quality assessment}

The formula to calculate the population prevalence (weighed prevalence (WP)) of $T$. gondii in all groups or subgroups, included in this meta-analysis, was $P=\sum$ (pi) $(1 / \mathrm{vi}) / \Sigma 1 / \mathrm{vi}$. We used the metaprop command of STATA, version 12.1 (StataCorp, College Station, TX, USA), for pooling proportions. We estimated $95 \%$ confidence intervals (CIs) using the score statistic and the exact binomial method, and Freeman-Tukey double arcsine transformation of proportions via the $\mathrm{ftt}$ option. Forest plots were drawn to display the variation of the seroprevalence of the Toxoplasma infection test positivity rate among all studies together with the pooled measure and subgroup analysis. Heterogeneity of the prevalence estimates between studies was determined by the $Q$ statistic and $I^{2}$ index, assuming that $I^{2}$ values of 25,50 , and $75 \%$ represented low, medium, and high heterogeneity, respectively. Therefore, we assess the quality of each study (Additional file 1: Table S1 and Additional file 2: Table S2). The influence of study characteristics (e.g. contact with cats and other pets; the consumption of raw meat, milk, soil, fruits, and vegetables; washing methods; age; occupational group; education level; place of residence; number of pregnancies and abortions; gestation age; the use of gloves when cutting meat; and 


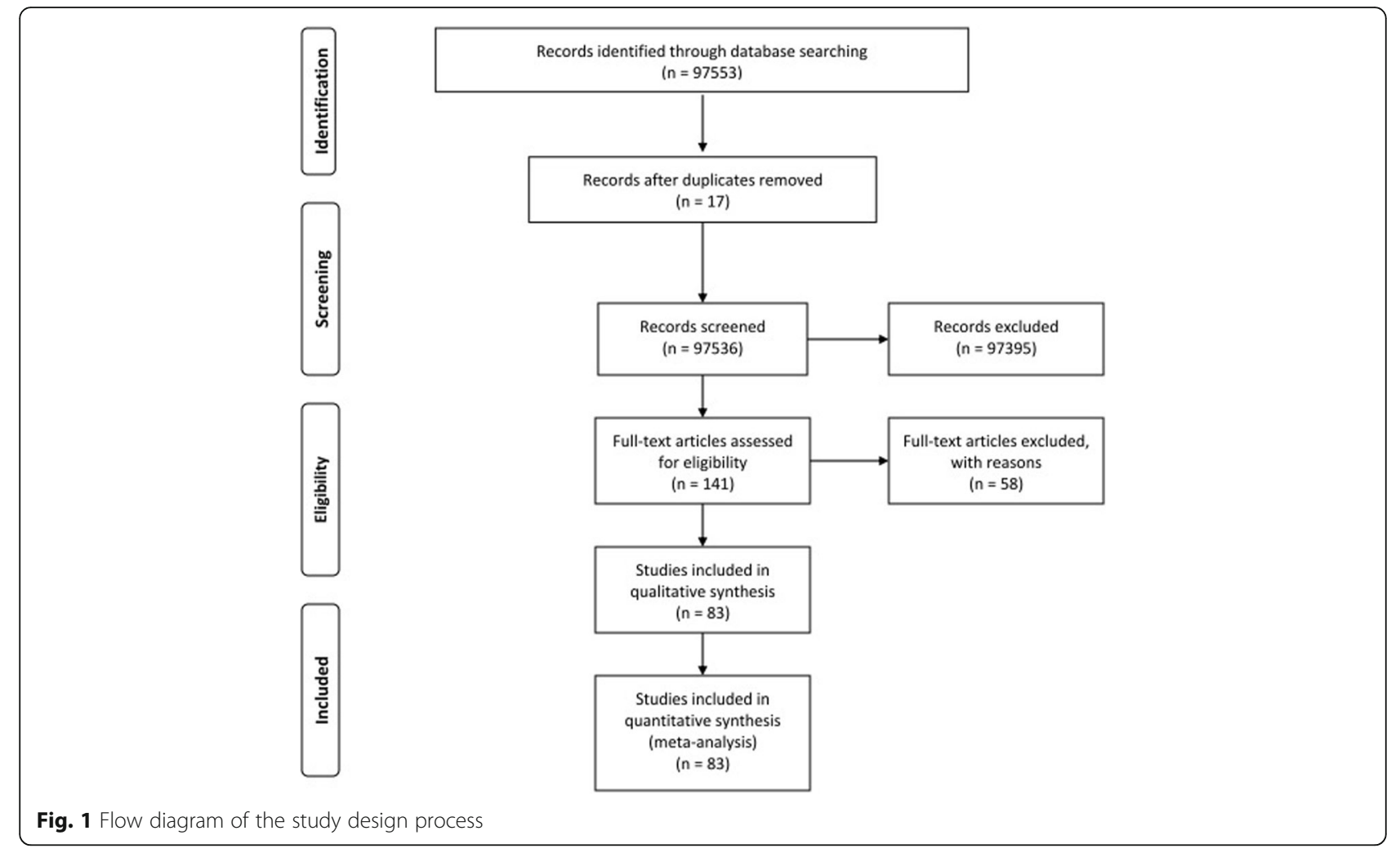

study quality) was explored using subgroup analysis and meta-regression.

\section{Results}

Of 97,553 literature searches from nine databases, 83 records were eligible to include in this systematic review and meta-analysis. Thirty-eight articles reported results about the seroprevalence of toxoplasmosis in women and girls of childbearing age, 45 about the seroprevalence of Toxoplasma infection among pregnant women. Approximately all the studies included in this metaanalysis had a cross-sectional design. Of 40,117 individuals, 16,698 cases had Ig against $T$. gondii and were included in the meta-analysis, followed by 39,837 individuals, with 15,822 positive cases for IgG, 16,590 with 652 positive cases for IgM, and 5447 with 224 cases positive for both IgG and IgM.

The prevalence of anti-Toxoplasma seropositivity in the girls group (i.e. women of childbearing age, high school girls, girl students from a university, girls referred to a health centre for pre-marriage examination, and non-pregnant women sent to a medical laboratory for examination) based on the random-effect model was $33 \%(95 \% \mathrm{CI}=23-43 \%)$. Figure 2 shows the forest plot diagram. About $67 \%$ of girls were seronegative and were not immune. The pooled estimations of IgG, IgM, and both IgG- and IgM-positive cases were 31\% (95\% CI = $21-41 \%)$, 5\% (95\% CI $=3-6 \%)$, and 3\% (95\% CI $=2-5 \%)$, respectively. Table 1 shows the baseline characteristic of the included studies.

Data analysis showed that there was a significant relationship between Toxoplasma seropositivity and contact with cats $(P=0.04)$. Although the seroprevalence of Toxoplasma infection was higher among individuals who had direct contact with cats (30\%); groups without contact with other animals (26\%); individuals who consumed raw meat (34\%), milk (45\%), and fruits or vegetables (24\%); individuals who washed vegetables or fruits with water $(27 \%)$ and cut meat without wearing gloves (18\%); individuals who had a low education level (63\%); and those who were employed (53\%) and were aged $>20$ years, there were no associations between these aforementioned factors and the rate of Toxoplasma infection. Table 2 shows the overall characteristics of the risk factors of the included studies.

The pooled estimation for the prevalence of antiToxoplasma antibodies in pregnant women using the random-effect model was $43 \%(95 \% \mathrm{CI}=38-48 \%)$. Figure 3 shows the forest plot diagram. The data indicated that $57 \%$ of pregnant women were seronegative and were not immune during pregnancy. Table 3 demonstrates the baseline characteristics of the included data. The pooled estimates of IgG, IgM, and both IgG- and IgM-positive cases were 40\% (95\% CI $=35-45 \%), 3 \% \quad(95 \% \mathrm{CI}=2-4 \%)$, and $4 \%$ (95\% CI $=2-5 \%)$, respectively. 


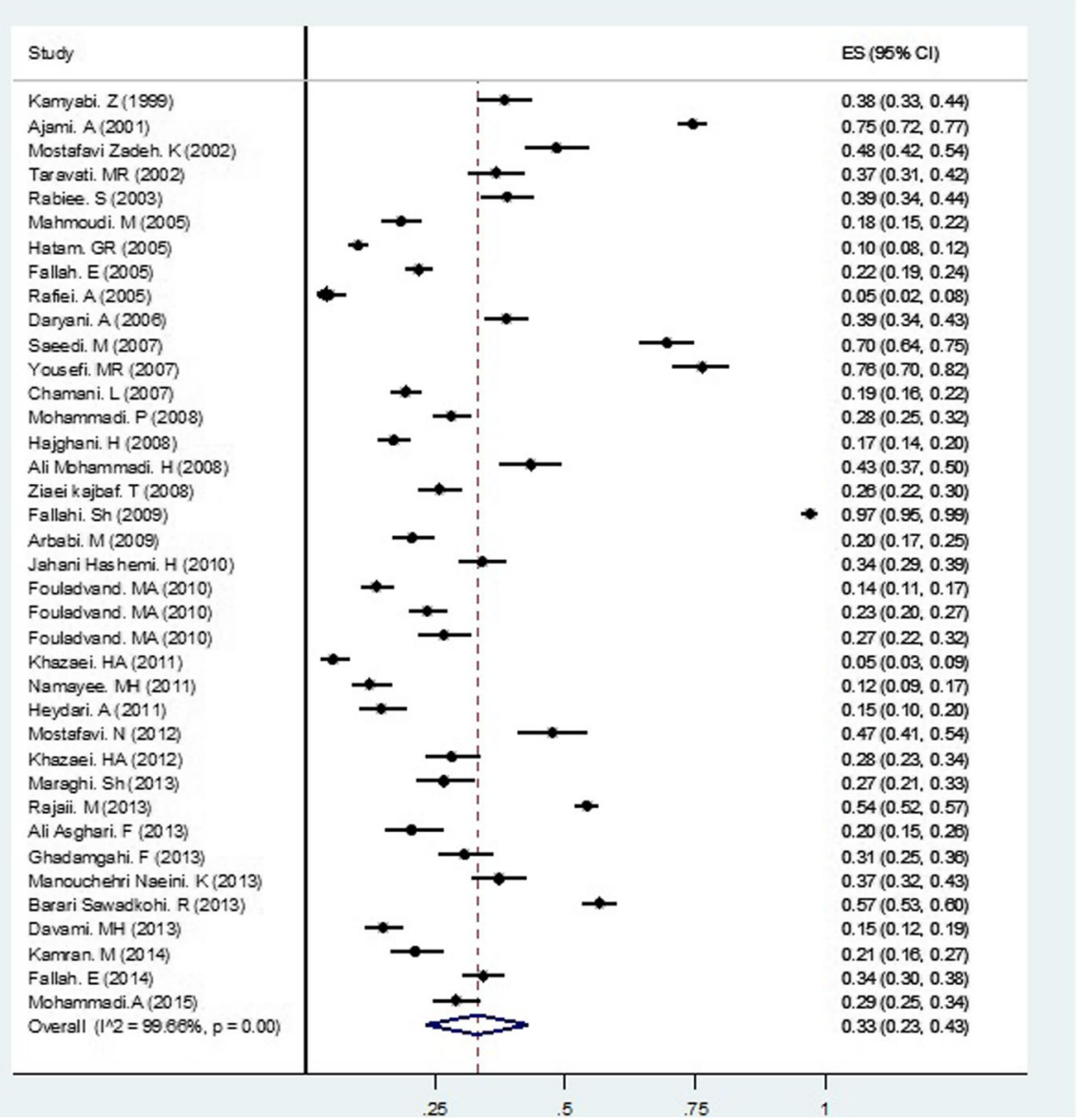

Fig. 2 Random-effect meta-analysis of pooled estimation of Toxoplasma gondii in girls and women of childbearing age group

In this group, there was a significant association among age groups $(P=0.004)$, contact with cats $(P=$ $0.005)$, gestation age of the pregnant women $(P=0.001)$, and the rate of infection. Data indicated that although the prevalence of $T$. gondii infection was higher among individuals who had direct contact with soil $(42 \%)$; consumed raw meat (41\%) and fruits or vegetables (39\%); washed vegetables or fruits with water (39\%); lived in rural areas (47\%); had a senior-junior high school education level (39\%); and were aged $>30$ years $(53 \%)$, there were no associations between these aforementioned factors and $T$. gondii antibody positivity. Table 4 shows the overall characteristics of the described risk factors.

\section{Discussion}

T. gondii has a wide range of distribution, and seroprevalence data indicate that toxoplasmosis is one of the most common human infections worldwide [15]. Acute infection with Toxoplasma during pregnancy and its outcome for the foetus and newborn continue to occur in Iran and in other countries, despite the fact that it can be prevented. A large body of the research about the seroepidemiology of toxoplasmosis in women has been performed in Iran because of the great importance of $T$. gondii as a public health problem, but there is a lack of comprehensive systematic and documented data in this area.

Among all nine databases searched from November 2014 to February 2017, 83 records involving 40,117 individuals and 16,698 cases containing immunoglobulin against $T$. gondii in groups of women were eligible to be included in this systematic review and meta-analysis. The present study showed that the seroprevalence of anti-T. gondii antibodies in Iranian pregnant women and women of childbearing age were 43 and 33\%, respectively. A higher prevalence of anti-T. gondii antibodies was observed in previous studies conducted in Iran: 55\% in patients who had received transplants, $50 \%$ in HIVinfected individuals, and $45 \%$ in patients with cancer [16]. The prevalence of toxoplasmosis from a survey administered to the general population in Iran was 39.3\% [9]. The data indicated that the seroprevalence of T. gondii in pregnant women in Europe varies from 9 to $67 \%$ [17]. Although some Asian countries such as Malaysia, 
Table 1 Girls and women of childbearing age group baseline characteristics of included studies

\begin{tabular}{|c|c|c|c|c|c|c|}
\hline Province & $\begin{array}{l}\text { Total } \\
\text { individuals }\end{array}$ & $\begin{array}{l}\text { lgG-positive cases } \\
(\%)\end{array}$ & $\begin{array}{l}\text { lgM-positive cases } \\
(\%)\end{array}$ & $\begin{array}{l}\text { IgG- and IgM-positive } \\
\text { cases (\%) }\end{array}$ & $\begin{array}{l}\text { Total prevalence } \\
(\%)\end{array}$ & Authors \\
\hline Kerman & 350 & $103(29.42)$ & $18(5.14)$ & $13(3.71)$ & $134(38.28)$ & Kamyabi et al., 1999 \\
\hline Mazandaran & 980 & 731 (74.59) & & & 731 (74.59) & Ajami et al., 2001 \\
\hline Isfahan & 273 & $132(48.35)$ & & & $132(48.35)$ & Mostafavi Zadeh et al., 2002 \\
\hline West Azerbaijan & 300 & $98(32.66)$ & $12(4)$ & & $110(36.66)$ & Taravati et al., 2002 \\
\hline Hamedan & 360 & $140(38.88)$ & & & $140(38.88)$ & Rabiee et al., 2003 \\
\hline Isfahan & 414 & $76(18.35)$ & & & $76(18.35)$ & Mahmoudi et al., 2005 \\
\hline Fars & 947 & $96(10.13)$ & & & $96(10.13)$ & Hatamet al., 2005 \\
\hline East Azerbaijan & 1000 & $218(21.8)$ & & & $218(21.8)$ & Fallah et al., 2005 \\
\hline Khuzestan & 259 & $12(4.63)$ & & & $12(4.63)$ & Rafiei et al., 2005 \\
\hline Ardabil & 504 & $175(34.72)$ & $20(3.96)$ & & 195 (38.69) & Daryani et al., 2006 \\
\hline Golestan & 300 & $145(48.33)$ & $35(11.66)$ & $29(9.66)$ & $209(69.66)$ & Saeedi et al., 2007 \\
\hline Mazandaran & 241 & $154(63.9)$ & $30(12.44)$ & & $184(76.34)$ & Yousefi et al., 2007 \\
\hline Tehran & 707 & 119 (16.83) & $17(2.4)$ & & $136(19.23)$ & Chamani et al., 2007 \\
\hline Kurdistan & 600 & $169(28.16)$ & & & $169(28.16)$ & Mohammadi et al., 2008 \\
\hline Kerman & 549 & $93(16.93)$ & & & $93(16.93)$ & Haj ghani et al., 2008 \\
\hline Ardabil & 272 & $115(42.27)$ & & $3(1.1)$ & $118(43.38)$ & Ali Mohammadi et al., 2008 \\
\hline Khuzestan & 400 & $103(25.75)$ & & & $103(25.75)$ & Ziaei kajbaf et al., 2008 \\
\hline Lorestan & 465 & $452(97.2)$ & & & $452(97.2)$ & Fallahi et al., 2009 \\
\hline Isfahan & 400 & $79(19.75)$ & $3(0.75)$ & & $82(20.5)$ & Arbabi et al., 2009 \\
\hline Qazvin & 400 & $136(34)$ & & & $136(34)$ & Jahani Hashemi et al., 2010 \\
\hline Bushehr & 491 & $54(10.99)$ & $8(1.62)$ & $5(1.01)$ & $67(13.64)$ & Fouladvand et al., 2010 \\
\hline Bushehr & 516 & $114(22.09)$ & $7(1.35)$ & & $121(23.44)$ & Fouladvand et al., 2010 \\
\hline Bushehr & 303 & $71(23.43)$ & $10(3.3)$ & & $81(26.73)$ & Fouladvand et al., 2010 \\
\hline Sistan and Baluchestan & 280 & & $15(5.35)$ & & $15(5.35)$ & Khazaie et al., 2011 \\
\hline South Khorasan & 300 & $37(12.33)$ & & & $37(12.33)$ & Namayee et al., 2011 \\
\hline Razavi Khorasan & 240 & $35(14.58)$ & & & $35(14.58)$ & Heydari et al., 2011 \\
\hline Isfahan & 217 & $103(47.46)$ & & & $103(47.46)$ & Mostafavi et al., 2012 \\
\hline Sistan and Baluchestan & 280 & $79(28.21)$ & & & $79(28.21)$ & Khazaei et al., 2012 \\
\hline Khuzestan & 240 & $28(11.66)$ & $29(12.08)$ & $7(2.91)$ & $64(26.66)$ & Maraghi et al., 2013 \\
\hline East Azerbaijan & 1659 & $898(54.12)$ & & & $898(54.12)$ & Rajaii et al., 2013 \\
\hline North Khorasan & 215 & $44(20.46)$ & & & $44(20.46)$ & Ali Asghari, et al., 2013 \\
\hline Tehran & 300 & $85(28.33)$ & $4(1.33)$ & $3(1)$ & $92(30.66)$ & Ghadamgahi et al., 2013 \\
\hline Mazandaran & 800 & $453(56.62)$ & & & $453(56.62)$ & Barari Sawadkohi et al., 2013 \\
\hline Fars & 403 & $52(12.9)$ & $8(1.98)$ & & $60(14.88)$ & Davami et al., 2013 \\
\hline $\begin{array}{l}\text { Chaharmahal } \\
\text { and Bakhtiari }\end{array}$ & 338 & $126(37.27)$ & & & $126(37.27)$ & Manouchehri et al., 2014 \\
\hline Ilam & 260 & $55(21.15)$ & & & $55(21.15)$ & Kamran et al., 2014 \\
\hline East Azerbaijan & 549 & $88(16.02)$ & $66(12.02)$ & $34(6.19)$ & $188(34.24)$ & Fallah et al., 2014 \\
\hline Markazi & 400 & $97(24.25)$ & $19(4.75)$ & & $116(29)$ & Mohammadi et al., 2015 \\
\hline
\end{tabular}

India, and Nepal have the highest seroprevalence of Toxoplasma infection in pregnant women (41.8-55.4\%), conversely, Korea and Vietnam report a low seropositivity rate of $T$. gondii ( 0.8 and $11.2 \%$, respectively) [1820]. In our neighbouring countries, Turkey and Pakistan, the anti-Toxoplasma antibody in pregnant women was found to be 33 and $19.25 \%$, respectively [21, 22]. However, in Turkey, the seroprevalence of Toxoplasma infection in women of reproductive age was determined to be 58.3 and $1 \%$ for IgG and IgM, respectively [23]. 
Table 2 Risk factors associated to seropositivity for Toxoplasma gondii in girls and women of childbearing age group

\begin{tabular}{|c|c|c|c|c|c|}
\hline Demographic factors & Total individuals & Positive cases & Pooled estimation (\%) & $P^{2}$ & $P$ value $^{a}$ \\
\hline \multicolumn{5}{|l|}{ Age } & 0.62 \\
\hline$\leq 20$ years & 2296 & 1040 & $45(95 \% \mathrm{Cl}=30$ to 60$)$ & 98.91 & \\
\hline$>20$ years & 4370 & 2294 & $39(95 \% \mathrm{Cl}=23$ to 56$)$ & 98.49 & \\
\hline \multicolumn{5}{|l|}{ Contact with cat } & 0.04 \\
\hline Yes & 1775 & 474 & $30(95 \% \mathrm{Cl}=24$ to 37$)$ & 87.44 & \\
\hline No & 3898 & 815 & $21(95 \% \mathrm{Cl}=16$ to 26$)$ & 93.78 & \\
\hline \multicolumn{5}{|c|}{ Contact with other animals } & 0.41 \\
\hline Yes & 657 & 182 & $26(95 \% \mathrm{Cl}=18$ to 35$)$ & 82.33 & \\
\hline No & 1443 & 295 & $21(95 \% \mathrm{Cl}=12$ to 30$)$ & 94.98 & \\
\hline \multicolumn{5}{|l|}{ Contact to meat } & 0.98 \\
\hline Yes & 646 & 204 & $28(95 \% \mathrm{Cl}=16$ to 42$)$ & 89.59 & \\
\hline No & 339 & 82 & $23(95 \% \mathrm{Cl}=19$ to 28$)$ & 96.53 & \\
\hline \multicolumn{5}{|l|}{ Meat consumption } & 0.12 \\
\hline Undercooked & 1755 & 466 & $34(95 \% \mathrm{Cl}=23$ to 46$)$ & 95.33 & \\
\hline Cooked & 2209 & 381 & $17(95 \% \mathrm{Cl}=12$ to 22$)$ & 89.25 & \\
\hline \multicolumn{5}{|c|}{ Raw vegetable/fruit consumption } & 0.25 \\
\hline Yes & 2645 & 631 & $24(95 \% \mathrm{Cl}=17$ to 31$)$ & 94.49 & \\
\hline No & & 47 & $17(95 \% \mathrm{Cl}=9$ to 27$)$ & 71.32 & \\
\hline \multicolumn{5}{|l|}{ Milk consumption } & 0.17 \\
\hline Pasteurized & 1264 & 276 & $21(95 \% \mathrm{Cl}=8$ to 38$)$ & 97.87 & \\
\hline Unpasteurized & 95 & 34 & $45(95 \% \mathrm{Cl}=19$ to 72$)$ & 78.93 & \\
\hline \multicolumn{5}{|l|}{ Educational status } & 0.37 \\
\hline Illiterate & 211 & 114 & $63(95 \% \mathrm{Cl}=37$ to 86$)$ & 91.70 & \\
\hline Junior/senior & 1064 & 553 & $50(95 \% \mathrm{Cl}=30$ to 70$)$ & 97.73 & \\
\hline High school & 987 & 555 & $52(95 \% \mathrm{Cl}=24$ to 80$)$ & 98.89 & \\
\hline Diploma/university & 863 & 320 & $47(95 \% \mathrm{Cl}=18$ to 77$)$ & 98.80 & \\
\hline \multicolumn{5}{|l|}{ Occupational group } & 0.37 \\
\hline Employee & 572 & 340 & $53(95 \% \mathrm{Cl}=33$ to 74$)$ & 99.17 & \\
\hline Housewife & 2389 & 1336 & $52(95 \% \mathrm{Cl}=30$ to 73$)$ & 95.28 & \\
\hline Students & 418 & 133 & $83(95 \% \mathrm{Cl}=16$ to 63$)$ & 95.95 & \\
\hline \multicolumn{5}{|c|}{ Wearing gloves during cutting meat } & 0.47 \\
\hline Yes & 250 & 31 & $12(95 \% \mathrm{Cl}=8$ to 17$)$ & 96.78 & \\
\hline No & 756 & 137 & $18(95 \% \mathrm{Cl}=15$ to 20$)$ & 96.78 & \\
\hline \multicolumn{5}{|l|}{ Washing vegetable/fruit } & 0.65 \\
\hline Water & 573 & 176 & $27(95 \% \mathrm{Cl}=12$ to 46$)$ & 95.36 & \\
\hline Antiseptic & 705 & 107 & $19(95 \% \mathrm{Cl}=10$ to 31$)$ & 89.76 & \\
\hline \multicolumn{5}{|l|}{ Residence } & 0.99 \\
\hline Urban & 5137 & 2011 & $33(95 \% \mathrm{Cl}=19$ to 49$)$ & 99.27 & \\
\hline Rural & 2924 & 1213 & $33(95 \% \mathrm{Cl}=22$ to 46$)$ & 97.53 & \\
\hline
\end{tabular}

${ }^{a}$ Meta-regression analysis

Toxoplasma infection's geographical distribution is related to several environmental factors (i.e. food habits, variations in climate, and contact with infected cat faeces) and sociodemographic factors (i.e. age, occupation, education, and residence) [24]. Any of these factors alone has little effect on the epidemiological status of Toxoplasma infection, but together, they can change the distribution pattern of the disease worldwide [9]. 


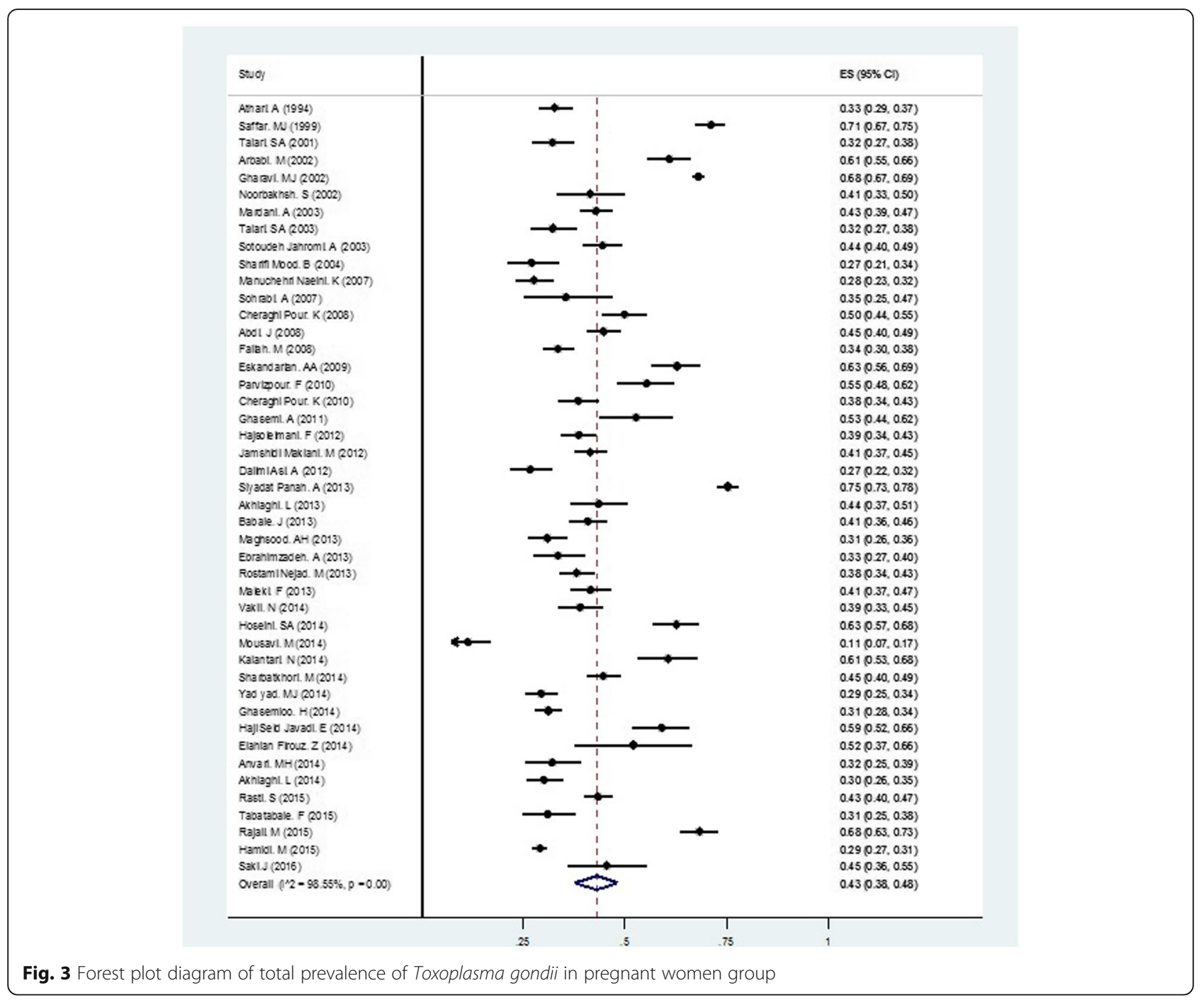

The geographical climate is one of the main factors of the disease. Our country has an arid climate, but the weather condition is variable. Some provinces such as Tehran, Fars, Kerman, and Khuzestan have various climates. Thus, an epidemiologic survey in this part of Iran is more difficult to administer. This variation of climatic conditions can introduce biases into the prevalence rate of Toxoplasma infection. In the northern part of Iran (around the Caspian Sea), there is a high prevalence of $T$. gondii infection, whereas in cold mountainous and hot provinces, lower seropositivity rates are found. The right climate status in the northern part provides a suitable condition for oocyst sporulation and survival in the environment. In mild and wet climates, the maturation of oocysts and transmission to a new host happens $[9,25]$. Additional file 3: Figure S1 shows the prevalence of total Toxoplasma antibodies in both girls and pregnant women in all parts of Iran.
The abundance of cats is another risk factor of Toxoplasma infection. Domestic cats are one of the main sources of infection. Our results showed that the antiToxoplasma antibody in cat and other pet owners was higher than that in individuals who did not own or have contact with domestic animals in both pregnant girls and those of childbearing age. Similar findings were reported by other studies [26, 27]. Cats excrete millions of oocysts after ingestion of even one tissue cyst or bradyzoite. In the environment, sporulated oocysts can outlast for months or even years in moist soil. Terrestrial insects such as earthworms, beetles, and even flies can extend oocysts from the soil, which leads to food contamination. Cats may be infected when hunting small mammals contaminated by tissue cysts. They can shed a large amount of oocysts via faeces in the environment. Food, water, farms, and gardens may be contaminated by their oocysts. Keeping cats in the house (e.g. keeping 
Table 3 Pregnant women group baseline characteristics of included studies

\begin{tabular}{|c|c|c|c|c|c|c|}
\hline Province & $\begin{array}{l}\text { Total } \\
\text { individuals }\end{array}$ & $\begin{array}{l}\text { IgG-positive cases } \\
(\%)\end{array}$ & $\begin{array}{l}\text { lgM-positive cases } \\
(\%)\end{array}$ & $\begin{array}{l}\text { IgG- and IgM-positive } \\
\text { cases (\%) }\end{array}$ & $\begin{array}{l}\text { Total prevalence } \\
(\%)\end{array}$ & Authors \\
\hline Kermanshah & 495 & $162(32.72)$ & & & $162(32.72)$ & Athari et al., 1994 \\
\hline Mazandaran & 612 & 435(71.07) & & & $435(71.07)$ & Saffar et al., 1999 \\
\hline Isfahan & 317 & $98(30.91)$ & $4(1.26)$ & & 102(32.17) & Talari et al., 2001 \\
\hline Isfahan & 340 & $207(60.88)$ & & & $207(60.88)$ & Arbabi et al., 2002 \\
\hline Tehran & 4120 & 2804(68.05) & & & $2804(68.05)$ & Gharavi et al., 2002 \\
\hline Tehran & 140 & $48(34.28)$ & 10(7.14) & & $58(41.42)$ & Noorbakhsh et al., 2002 \\
\hline Isfahan & 270 & $72(26.66)$ & 15(5.55) & & $87(32.22)$ & Talari et al., 2003 \\
\hline Hormozgan & 418 & 143(34.21) & $33(7.89)$ & 10(2.39) & 186(44.49) & SotoudehJahromi et al., 2003 \\
\hline Qom & 600 & $257(42.83)$ & & & $257(42.83)$ & Mardani et al., 2003 \\
\hline Sistan and Baluchestan & 200 & $54(27)$ & & & $54(27)$ & Sharifi Mood et al., 2004 \\
\hline $\begin{array}{l}\text { Chaharmahal } \\
\text { and Bakhtiari }\end{array}$ & 384 & $106(27.60)$ & & & 106(27.60) & Manuchehri et al., 2007 \\
\hline Khuzestan & 79 & $28(35.44)$ & & & 28(35.44) & Sohrabi et al., 2007 \\
\hline Ilam & 553 & $247(44.66)$ & & & $247(44.66)$ & Abdi et al., 2008 \\
\hline Hamedan & 576 & 193(33.50) & & & 193(33.50) & Fallah et al., 2008 \\
\hline Qazvin & 255 & $160(62.74)$ & & & $160(62.74)$ & Eskandarian et al., 2009 \\
\hline Kurdistan & 201 & $54(26.86)$ & 24(11.94) & $33(16.41)$ & $111(55.22)$ & Parvizpour et al., 2010 \\
\hline Lorestan & 390 & 121(31.02) & $29(7.43)$ & & 150(38.46) & Cheraghi Pour et al., 2010 \\
\hline Lorestan & 331 & 130(39.27) & $35(10.57)$ & & 165(49.84) & Cheraghi Pour et al., 2010 \\
\hline Isfahan & 127 & $67(52.75)$ & & & $67(52.75)$ & Ghasemi et al., 2011 \\
\hline Zanjan & 500 & 186(37.2) & $7(1.4)$ & & 193(38.60) & Hajsoleimani et al., 2012 \\
\hline Hormozgan & 608 & $252(41.44)$ & & & $252(41.44)$ & JamshidiMakiani et al., 2012 \\
\hline East Azerbaijan & 300 & $79(26.33)$ & $1(0.33)$ & & $80(26.66)$ & DalimiAsl et al., 2012 \\
\hline Mazandaran & 1057 & $739(69.91)$ & $57(5.39)$ & & 796(75.30) & SiyadatPanah et al., 2013 \\
\hline Qom & 200 & $76(38)$ & $11(5.5)$ & & $87(43.50)$ & Akhlaghi et al., 2013 \\
\hline Razavi Khorasan & 419 & 144(34.36) & & $27(18.75)^{a}$ & $171(40.81)$ & Babaie et al., 2013 \\
\hline Hamedan & 350 & $105(30)$ & & $3(2.85)^{b}$ & 108(30.85) & Maghsood et al., 2013 \\
\hline Sistan and Baluchestan & 221 & 68(30.76) & $3(1.35)$ & $3(1.35)$ & 74(33.48) & Ebrahimzadeh et al., 2013 \\
\hline Lorestan & 496 & 154(31.04) & & $35(22.72)^{c}$ & 189(38.10) & RostamiNejad et al., 2013 \\
\hline Qom & 400 & $145(36.25)$ & $21(5.25)$ & & $166(41.50)$ & Maleki et al., 2013 \\
\hline Markazi & 308 & 117(37.98) & & $3(1.74)^{d}$ & 120(38.96) & Vakil et al., 2014 \\
\hline Mazandaran & 289 & $170(58.82)$ & $7(2.42)$ & $4(1.38)$ & $181(62.62)$ & Hoseini et al., 2014 \\
\hline Sistan and Baluchestan & 185 & 19(10.27) & $1(0.54)$ & $1(0.54)$ & $21(11.35)$ & Mousavi et al., 2014 \\
\hline Mazandaran & 175 & $106(60.57)$ & & & $106(60.57)$ & Kalantari et al., 2014 \\
\hline Golestan & 555 & $221(39.81)$ & 19(3.42) & $8(1.44)$ & $248(44.68)$ & Sharbatkhori et al., 2014 \\
\hline Khuzestan & 501 & $137(27.34)$ & $7(1.39)$ & $3(0.59)$ & 147(29.34) & Yadyad et al., 2014 \\
\hline Tehran & 785 & 244(31.08) & & & 244(31.08) & Ghasemloo et al., 2014 \\
\hline East Azerbaijan & 195 & 115(58.97) & & & 115(58.97) & Haji SeidJavadi et al., 2014 \\
\hline Mazandaran & 50 & $26(52)$ & & & $26(52)$ & ElahianFirouz et al., 2014 \\
\hline Yazd & 181 & $58(32.04)$ & & & $58(32.04)$ & Anvari et al., 2014 \\
\hline Alborz & 400 & $116(29)$ & $4(1)$ & & $120(30)$ & Akhlaghi et al., 2014 \\
\hline Isfahan & 798 & $341(42.73)$ & $5(0.62)$ & & $346(43.35)$ & Rasti et al., 2015 \\
\hline
\end{tabular}


Table 3 Pregnant women group baseline characteristics of included studies (Continued)

\begin{tabular}{|c|c|c|c|c|c|}
\hline Qazvin & 200 & $58(29)$ & $4(2)$ & $62(31)$ & Tabatabaieet al., 2015 \\
\hline East Azerbaijan & 391 & $267(68.28)$ & & $267(68.28)$ & Rajaii et al., 2015 \\
\hline Hamedan & 2523 & $681(26.99)$ & $51(2.02)$ & $732(29.01)$ & Hamidi et al., 2015 \\
\hline Khuzestan & 110 & $47(42.72)$ & $3(2.72)$ & $50(45.45)$ & Saki et al., 2016 \\
\hline
\end{tabular}

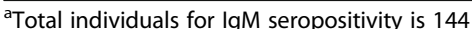

${ }^{\mathrm{b}}$ Total individuals for IgM seropositivity is 105

'Total individuals for IgM seropositivity is $\mathbf{1 5 4}$

${ }^{\mathrm{d}}$ Total individuals for IgM seropositivity is 172

them indoors or outdoors), especially in high-risk groups such as seronegative pregnant women who are susceptible to Toxoplasma infection, needs more consideration [28]. Previous data have indicated that dog fur that has come in contact with cat faeces may be one of the factors of oocyst transmission to humans [2].

In our study, T. gondii showed a higher antibody titre in individuals who consume undercooked meat, milk, vegetables, and fruits and washed them with water only instead of detergent in both aforementioned groups. Lopes et al. and Gelaye et al. showed the same results $[26,29]$. The consumption of meat from domestic animals contaminated with tissue cysts is one of the main sources of infection. The risk of acquiring $T$. gondii via contaminated meat with tissue cysts varies between cultural and eating habits in various communities. However, meat is one of the major sources of Iranian meals; thus, the consumption of undercooked meat can lead to the transmission of parasites. There is a risk of Toxoplasma infection by consuming dairy products. Tachyzoites are orally infectious because they can survive in pepsin and trypsin. The consumption of milk containing tachyzoites in girls and women of childbearing age with no prior contact to the organism can lead to horizontal transmission and clinical infection. In seronegative women during pregnancy, the consumption of undercooked meats such as kebab (a meat product like sausage), dairy products, raw vegetables, and fruits can lead to congenital toxoplasmosis, which is a serious problem $[9,30]$.

Our data showed that the seropositivity of $T$. gondii infection among various occupations in both groups was different. In women of childbearing age and the girls group, the seroepidemiology of $T$. gondii in employees was a little higher than other jobs, but this difference was not significant. Our result was comparable to a study performed in Brazil, which showed a high prevalence of infection in this group [27]. However, in pregnant women, antibody titres were the same in both groups. Women spend more time cooking, tasting foods during meal preparation, handling and chopping meat in the kitchen, taking care of pets at home, gardening, and cleaning and washing vegetables and fruits. This finding explains why the seropositivity of infection in individuals who have contact with soil during gardening and women who chop meat without wearing gloves is higher than that in groups who do not have exposure to soil and raw meat. In various parts of the world, $T$. gondii oocysts have been isolated from soil samples [2].

Published studies have indicated that in women of childbearing age, by increasing the level of education, a rising trend in T. gondii seropositivity was observed. Evidence from a study by Hung et al. supported our finding [31]. The authors suggested that women with an academic education should have more knowledge related to Toxoplasma biology and its prevention and control strategies. The lack of effective information about this disease such as the route of transmission during pregnancy and poor socioeconomic status can increase the risk of infection.

The seroprevalence and serologically positive cases increased by age in pregnant groups. Nimiri et al. demonstrated that a higher seropositivity rate was seen in older age groups than in younger age groups [32]. The reason for this has not yet been discussed and it is not clear, but authors suggested the following reasons for infection: the prolonged exposure to the risk factors, transmission route, and lack of public awareness about preventive methods.

In the current study, the seroprevalence of $T$. gondii in pregnant women who lived in rural areas was higher than those in urban areas. In 2009, Lopes et al. found similar results with our findings [26]. During the first trimester of pregnancy, the risk of acquired congenital infection and impact on the foetus is $10-15 \%$. However, in the second and third trimesters, the risk of foetal infection increases $(60-90 \%)$ and also the effects on the foetus are milder [30, 33].

In the present study, the seropositivity rate of infection in the first trimester of pregnancy was higher than that in the second and third trimesters. In all women during conception, ideally in the first trimester, a serological screening test for $T$. gondii IgG and IgM detection are feasible [34]. This kind of screening helps clinicians detect seroconversion individuals and provide early treatment for infection [35]. In our study, multi-gravid women had a higher prevalence of $T$. gondii infection, and the prevalence was proportionally increased with an increasing number of children. Null gravid women 
Table 4 Risk factors associated to seropositivity for Toxoplasma gondii in pregnant women group

\begin{tabular}{|c|c|c|c|c|c|}
\hline Demographic factors & Total individuals & Positive cases & Pooled estimation (\%) & $R^{2}$ & $P$ value $^{a}$ \\
\hline \multicolumn{5}{|l|}{ Age } & 0.004 \\
\hline$\leq 30$ years & 5332 & 2041 & $34(95 \% \mathrm{Cl}=26$ to 43$)$ & 97.69 & \\
\hline$>30$ years & 1414 & 772 & $53(95 \% \mathrm{Cl}=45$ to 61$)$ & 87.70 & \\
\hline \multicolumn{5}{|l|}{ Contact with cat } & 0.005 \\
\hline Yes & 1779 & 787 & $44(95 \% \mathrm{Cl}=36$ to 52$)$ & 89.17 & \\
\hline No & 2410 & 716 & $27(95 \% \mathrm{Cl}=20$ to 34$)$ & 92.53 & \\
\hline \multicolumn{5}{|l|}{ Contact with soil } & 0.92 \\
\hline Yes & 63 & 27 & $42(95 \% \mathrm{Cl}=30$ to 54$)$ & 92.72 & \\
\hline No & 929 & 310 & $33(95 \% \mathrm{Cl}=30$ to 36$)$ & 92.72 & \\
\hline \multicolumn{5}{|l|}{ Meat consumption } & 0.4 \\
\hline Undercooked & 1450 & 603 & $41(95 \% \mathrm{Cl}=28$ to 53$)$ & 95.05 & \\
\hline Cooked & 1814 & 645 & $35(95 \% \mathrm{Cl}=29$ to 42$)$ & 88.62 & \\
\hline \multicolumn{5}{|c|}{ Raw vegetable/fruit consumption } & 0.46 \\
\hline Yes & 1463 & 570 & $39(95 \% \mathrm{Cl}=25$ to 54$)$ & 96.90 & \\
\hline No & 520 & 164 & $31(95 \% \mathrm{Cl}=26$ to 36$)$ & 29.12 & \\
\hline \multicolumn{5}{|l|}{ Washing vegetable/fruit } & 0.64 \\
\hline Water & 847 & 358 & $39(95 \% \mathrm{Cl}=21$ to 58$)$ & 96.85 & \\
\hline Antiseptic & 602 & 212 & $34(95 \% \mathrm{Cl}=23$ to 47$)$ & 88.09 & \\
\hline \multicolumn{5}{|l|}{ Residence } & 0.55 \\
\hline Rural & 1796 & 762 & $47(95 \% \mathrm{Cl}=38$ to 55$)$ & 91.72 & \\
\hline Urban & 2361 & 1017 & $43(95 \% \mathrm{Cl}=34$ to 52$)$ & 94.57 & \\
\hline \multicolumn{5}{|l|}{ Occupational group } & 0.94 \\
\hline Employee & 143 & 68 & $47(95 \% \mathrm{Cl}=35$ to 59$)$ & 48.56 & \\
\hline Housewife & 1359 & 594 & $47(95 \% \mathrm{Cl}=39$ to 55$)$ & 86.58 & \\
\hline \multicolumn{5}{|l|}{ Educational status } & 0.67 \\
\hline Illiterate & 329 & 108 & $34(95 \% \mathrm{Cl}=25$ to 44$)$ & 63.80 & \\
\hline Junior/senior & 1617 & 665 & $39(95 \% \mathrm{Cl}=32$ to 47$)$ & 88.35 & \\
\hline High school/diploma & 1410 & 457 & $31(95 \% \mathrm{Cl}=26$ to 36$)$ & 73.55 & \\
\hline University & 493 & 189 & $36(95 \% \mathrm{Cl}=27$ to 45$)$ & 76.63 & \\
\hline \multicolumn{5}{|l|}{ Gestation age } & 0.001 \\
\hline 1st trimester & 570 & 258 & $46(95 \% \mathrm{Cl}=40$ to 51$)$ & 46.05 & \\
\hline 2nd trimester & 491 & 192 & $39(95 \% \mathrm{Cl}=35$ to 43$)$ & 0 & \\
\hline 3rd trimester & 594 & 193 & $32(95 \% \mathrm{Cl}=29$ to 36$)$ & 0 & \\
\hline \multicolumn{5}{|l|}{ Number of pregnancy } & 0.42 \\
\hline Null gravid & 363 & 143 & $41(95 \% \mathrm{Cl}=23$ to 61$)$ & 92.76 & \\
\hline Multi-gravid & 452 & 228 & $53(95 \% \mathrm{Cl}=36$ to 69$)$ & 92.16 & \\
\hline \multicolumn{5}{|l|}{ History of abortion } & 0.22 \\
\hline Yes & 4285 & 1666 & $44(95 \% \mathrm{Cl}=37$ to 50$)$ & 94.60 & \\
\hline No & 3058 & 1170 & $38(95 \% \mathrm{Cl}=32$ to 44$)$ & 90.93 & \\
\hline
\end{tabular}

${ }^{a}$ Meta-regression analysis

had a prevalence of $41 \%$, whereas women with more than one child had a prevalence of $53 \%$. Our results showed a trend towards an increasing risk of positive $T$. gondii antibodies with increasing parity. In our study, the rate of anti-Toxoplasma antibodies among women with spontaneous abortion was $44 \%$. This finding is in agreement with reports from Taiwan and Ethiopia [29, 31]. 
The most commonly used serological method of available data on $T$. gondii epidemiologic survey in both groups was ELISA. ELISA is a quantitative and inexpensive tool with a sensitivity and specificity of 100 and 98.4\%, respectively [24]. The second common serological method is IFA (sensitivity, 95\%; specificity, 96\%). Albeit IFA is cheap, manageable, and safe, it is a manual tool and ultraviolet light microscopy is needed [9]. Additional file 4: Table S3 and Additional file 5: Table S4 summarize the characteristic of methods used in the included studies.

The prevention and control of Toxoplasma infection rely on sufficient information about parasite epidemiology. The knowledge on $T$. gondii seroprevalence, risk factors, and prevention strategies can lead to efficient incidence reduction [36]. The general population knows little about congenital toxoplasmosis and the risk of disease. Awareness of the risk factors of toxoplasmosis makes it possible for health authorities to define specific preventive strategies for high-risk populations. Primary prevention includes educational materials that contain the routes of how to prevent infection in women during pregnancy, which have resulted in reducing the prevalence of the seroconversion population.

Secondary prevention includes serological screening. The transmission of $T$. gondii to the foetus always happens during or before conception. In healthy women with previous infection, transmission to the foetus rarely occurs [37]. In both IgG- and IgM-negative cases, there is no serologic evidence of prior exposure to $T$. gondii, and the risk of congenital toxoplasmosis is high. Thus, they require serial testing during gestation. Anti-Toxoplasma IgG-positive women should be tested for the IgM antibody, and in IgM-positive cases, confirmative tests are needed. In women with IgG-positive and IgMnegative antibodies, the gestation age is very important. In women at $<18$ weeks of gestation, it means past infection and the risk of congenital toxoplasmosis is zero. However, in women at $>18$ weeks of gestation, it is difficult to predict whether exposure happened in the past or during conception. In anti-Toxoplasma IgG-negative and IgM-positive cases, a serological test should be repeated after 3 weeks. In this group, two conditions can occur: the antibody titre persists (IgG- and $\operatorname{IgM}+$ ) or the IgG antibody changes to positive (IgG+ and IgM+). Management of the first group is the same as that for IgG- and IgM- patients, and in the second group, seroconversion occurs. In this group, the risk of $T$. gondii transmission to the foetus is high, and treatment, amniotic fluid polymerase chain reaction, and ultrasound should be performed [34].

The results show that there is heterogeneity across the studies as illustrated by the forest plot. The dissimilarity, sensitivity, and specificity of several methods used in various studies, differences in the sample size, nutritional habits, and environmental factors such as the geographical climate can result in this heterogeneity.

There are many studies based on the seroepidemiologic survey on women with toxoplasmosis in Iran, but there has not been a comprehensive systematic and documented report on this topic, except two articles on the epidemiology of Toxoplasma in women, which were not comprehensive $[10,38]$. The present article fulfils this gap. Our systematic review and meta-analysis has certain limitations. The major limitations include the following: (1) there was no uniform sample size, (2) different methods with various sensitivity and specificity were used, (3) and the epidemiological results were heterogeneous. These aforementioned factors may have biased the prevalence of Toxoplasma infection in the population of Iranian women.

\section{Conclusions}

This is the first comprehensive systematic review and meta-analysis of $T$. gondii in the overall population of women in our country. The data showed that $57 \%$ of Iranian pregnant women and $67 \%$ of girls and women of childbearing age were seronegative for Toxoplasma and susceptible to acute infection. Seronegative women are a high-risk group for congenital toxoplasmosis and should be monitored. We suggest that peer-led educational activities such as seminars and workshops are very effective, but they require great organizational efforts and lots of money and time. In Iran, there is no screening programme for women or seronegative pregnant women during gestation, but spouses are referred to health centres for premarital laboratory tests. It is necessary for the Ministry of Health to establish a screening programme and training course for couples who are referred to counselling departments for pre-marriage examinations. The risk factors for Toxoplasma should be documented in pamphlets and brochures with illustrations to make them easy to understand. However, didactic videos may serve as an effective teaching tool in these places. Importantly, health care organizations need to implement vast seroepidemiologic surveys on Toxoplasma infection in women and the disease risk factors using standardized methods, an identical sample size, and unique risk factors, to determine the true seropositivity rate in all provinces.

\section{Additional files}

Additional file 1: Table S1. Girls group quality assessment table. (DOC $81 \mathrm{~kb})$

Additional file 2: Table S2. Pregnant women group quality assessment table. (DOC $92 \mathrm{~kb}$ )

Additional file 3: Figure S1. Prevalence rate of Toxoplasma total antibodies in both groups in different provinces of Iran. (JPG $380 \mathrm{~kb}$ ) 
Additional file 4: Table S3. Girls and women of childbearing age group methods of included data. (DOCX $16 \mathrm{~kb}$ )

Additional file 5: Table S4. Pregnant women group methods of included data. (DOCX $16 \mathrm{~kb}$ )

\section{Acknowledgements}

The authors thank the Deputy of Research and Toxoplasmosis Research Centre (TRC) of Mazandaran University of Medical Sciences, Sari, Iran, for their kind provision.

\section{Funding}

No funding was received for this paper.

\section{Availability of data and materials}

Not applicable.

\section{Authors' contributions}

All authors made a substantial contribution to this review. AM, AD, and MS participated in the study design. SS, AA, AS, SAH, and MTR participated in the data collection and literature searches. AM, AD, AAP, MS, SS, AA, AS, SAH, and MTR were involved and contributed to the data interpretation. AM, SS, and $\mathrm{AA}$ contributed to the creation of the figures and tables. AAP and AD participated in the data analysis. AM involved in the drafting of the article. $A D, A A P, M S, S S, A A, A S, S A H$, and MTR contributed to the critical revision of the article. All authors approved the final article for intellectual content with approval for publication with agreement towards accountability for all aspects of the article in regard to accuracy.

\section{Competing interests}

The authors declare that they have no competing interests

\section{Consent for publication}

Not applicable.

\section{Ethics approval and consent to participate}

Not applicable.

\section{Publisher's Note}

Springer Nature remains neutral with regard to jurisdictional claims in published maps and institutional affiliations.

\section{Author details}

${ }^{1}$ Toxoplasmosis Research Center, Mazandaran University of Medical Sciences, P. O. Box 48168-95475, Sari, Iran. ²Parasitology and Mycology Department, School of Medicine, Mazandaran University of Medical Sciences, Sari, Iran. ${ }^{3}$ Student Research Committee, Mazandaran University of Medical Sciences, Sari, Iran. ${ }^{4}$ Community Medicine Department, School of Medicine,

Mazandaran University of Medical Sciences, Sari, Iran.

\section{Received: 14 December 2016 Accepted: 31 March 2017}

\section{Published online: 12 April 2017}

\section{References}

1. Flegr J, Prandota J, Sovičková M, et al. Toxoplasmosis - a global threat. Correlation of latent toxoplasmosis with specific disease burden in a set of 88 countries. Plos One. 2014;9(3):e90203. Lancet Infect Dis. 2005;5(12):763 - 74.

2. Tenter AM, Heckeroth AR, Weiss LM. Toxoplasma gondii: from animals to humans. Int J Parasitol. 2000;30:1217-58.

3. El Deeba HK, Salah Eldin H, Khodeerc S, et al. Prevalence of Toxoplasma gondii infection in antenatal population in Menoufia, governorate Egypt. Acta Trop. 2012;124:185-91.

4. Flegr J, Preiss M, Klose J, et al. Decreased level of psychobiological factor novelty seeking and lower intelligence in men latently infected with the protozoan parasite Toxoplasma gondii dopamine, a missing link between schizophrenia and toxoplasmosis? Biol Psychol. 2003;63:253-68.

5. Torgerson PR, Mastroiacovo P. The global burden of congenital toxoplasmosis: a systematic review. Bull World Health Organ. 2013;91:501-8.

6. Kirby T. Calls for more detailed studies on toxoplasmosis. Lancet Infect Dis, 2012;12(12):912-3.
7. Goebel WS, Conway JH, Faught $\mathrm{P}$, et al. Disseminated toxoplasmosis resulting in graft failure in a cord blood stem cell transplant recipient. Pediatr Blood Cancer. 2007;48:222-6.

8. Editorial. Toxoplasma gondii: an unknown quantity. Lancet Infect Dis. 2012 12(10):737.

9. Daryani A, Sarvi S, Aarabi M, et al. Seroprevalence of Toxoplasma gondii in the Iranian general population: a systematic review and meta-analysis. Acta Trop. 2014;137:185-94.

10. Borna S, Shariat M, Fallahi M, et al. Prevalence of immunity to toxoplasmosis among Iranian childbearing age women: systematic review and metaanalysis. Iran J Reprod Med. 2013;11(11):861-8.

11. Montoya JG, Boothroyd JC, Kovaks JA. Toxoplasma gondii. In: Mandell GL, Bennett JE, Dolin R, editors. Principles and practice of infectious diseases. Philadelphia: Churchill Livingstone; 2010. p. 3495-526.

12. Sakikawa M, Noda S, Hanaoka M, et al. Anti-Toxoplasma antibody prevalence, primary infection rate, and risk factors in a study of toxoplasmosis in 4,466 pregnant women in Japan. Clin Vaccine Immunol. 2012;19(3):365-7.

13. Minkoff $\mathrm{H}$, Remington JS, Holman S, et al. Vertical transmission of Toxoplasma by human immunodeficiency virus-infected women. Am J Obstet Gynecol. 1997:176(3):555-9.

14. Lindström I, Kaddu M, Kironde F, et al. Prevalence of latent and reactivated Toxoplasma gondii parasites in HIV-patients from Uganda. Acta Trop. 2006; 100:218-22.

15. Sarvi S, Daryani A, Rahimi MT, et al. Cattle toxoplasmosis in Iran: a systematic review and meta-analysis. Asian Pac J Trop Dis. 2015;8:120-6.

16. Ahmadpour E, Daryani A, Sharif M, et al. Toxoplasmosis in immunocompromised patients in Iran: a systematic review and metaanalysis. J Infect Dev Ctries. 2014;8(12):1503-10.

17. Meerburg BG, Kijlstra A. Changing climate-changing pathogens: Toxoplasma gondii in North-Western Europe. Parasitol Res. 2009;105:17-24.

18. Song KJ, Shin JC, Shin HJ, et al. Seroprevalence of toxoplasmosis in Korean pregnant women. Korean J Parasitol. 2005:43:69-71.

19. Buchy P, Follezou JY, Lien TX, et al. Serological study of toxoplasmosis in Vietnam in a population of drug users (Ho Chi Minh city) and pregnant women (NhaTrang). Bull Soc Pathol Exot. 2003:96:46-7.

20. Rai SK, Shibata H, Sumi K, et al. Toxoplasma antibody prevalence in Nepalese pregnant women and women with bad obstetric history. SE Asian J Trop Med Public Health Med. 1998;29:739-43.

21. Ertug S, Okyay $P$, Turkmen $M$, et al. Seroprevalence and risk factors for Toxoplasma infection among pregnant women in Aydin province, Turkey. BMC Public Health. 2005:5(1):1-6.

22. Faisal IA, Khan AU, Waqar M, et al. Distribution of Toxoplasma gondii in the pregnant women of district Swabi Khyber Pakhtunkhwa Pakistan. World Appl Sci J. 2014:29(1):77-9.

23. Yentur DN, Simsek Z, Gurses G, et al. Prevalence and associated risk factors of Toxoplasma gondii in female farm workers of southeastern Turkey. J Infect Dev Ctries. 2015;9(01):087-93.

24. Galvan Ramirez MDLL, Troyo R, Roman S, et al. A systematic review and meta-analysis of Toxoplasma gondii infection among the Mexican population. Parasit Vectors. 2012;5:271.

25. Sharif M, Sarvi S, Shokri A, et al. Toxoplasma gondii infection among sheep and goats in Iran: a systematic review and meta-analysis. Parasitol Res. 2015; 114:1-16.

26. Lopes FMR, Mitsuka Bregano R, Gonçalves DD, et al. Factors associated with seropositivity for anti-Toxoplasma gondii antibodies in pregnant women of Londrina, Paraná, Brazil. Mem Inst Oswaldo Cruz. 2009;104(2):378-82.

27. Sroka S, Bartelheimer N, Winter A, et al. Prevalence and risk factors of toxoplasmosis among pregnant women in Fortaleza, Northeastern Brazil. Am J Trop Med Hyg. 2010;83(3):528-33.

28. Hill D, Dubey JP. Toxoplasma gondii: transmission, diagnosis and prevention. Clin Microbiol Infect. 2002:8:634-40.

29. Gelaye W, Kebede T, Hailu A. High prevalence of anti-Toxoplasma antibodies and absence of Toxoplasma gondii infection risk factors among pregnant women attending routine antenatal care in two hospitals of Addis Ababa, Ethiopia. Int J Infect Dis. 2015;34:41-5.

30. Dubey JP, Jones JL. Toxoplasma gondii infection in humans and animals in the United States. Int J Parasitol. 2008:38:1257-78.

31. Hung CS, Su HW, Lee Y, et al. Seroprevalence, seroconversion, and toxoplasmosis risk factors among pregnant women in Taipei City, Taiwan Japanese J Infect Dis. 2015;68(4):312-17. 
32. Nimiri L, Pelloux H, Elkhatib L. Detection of Toxolasma gondii and specific antibodies in high-risk pregnant women. Am J Trop Med Hyg. 2004;71(6): 831-5.

33. Ayi I, Odoi-Kpoti Sowah A, Awusah Blay E, Suzuki T, Ohta N, Ayeh-Kumi PF. Toxoplasma gondii infections among pregnant women, children and HIVseropositive persons in Accra, Ghana. Trop Med Health. 2016;44:17.

34. Montaya JG, Remington JS. Management of Toxoplasma gondii infection during pregnancy. Clin Pract. 2008;47:554-66.

35. Elsheikha HM. Congenital toxoplasmosis: priorities for further health promotion action. Public Health. 2008;122:335-53.

36. Moghazy El, Kandil FM, Shaapan RM. Toxoplasma gondii comparison of some erological tests for antibody detection in sera and naturally infected pigs. World Zool. 2011;6:204-8

37. Sharif M, Daryani A, Barzegar G, Nasrolahei M. A seroepidemiological survey for toxoplasmosis among schoolchildren of Sari, Northern Iran. Trop Biomed. 2010;27:220-5.

38. Foroutan-Rad M, Khademvatan S, Majidiani H, et al. Seroprevalence of Toxoplasma gondii in the Iranian pregnant women: a systematic review and meta-analysis. Acta Trop. 2016;158:160-9.

\section{Submit your next manuscript to BioMed Central} and we will help you at every step:

- We accept pre-submission inquiries

- Our selector tool helps you to find the most relevant journal

- We provide round the clock customer support

- Convenient online submission

- Thorough peer review

- Inclusion in PubMed and all major indexing services

- Maximum visibility for your research

Submit your manuscript at www.biomedcentral.com/submit 